\title{
Extraction and Analysis of Tomato Seed Oil
}

\author{
F. J. Eller · J. K. Moser · J. A. Kenar • \\ S. L. Taylor
}

Received: 9 October 2009/Revised: 19 February 2010/Accepted: 24 February 2010/Published online: 21 March 2010

(C) US Government 2010

\begin{abstract}
Tomato seeds represent a very large waste byproduct from the processing of tomatoes into products such as tomato juice, sauce and paste. One potential use for these seeds is as a source of vegetable oil. This research investigated the oil content of tomato seeds using several extraction techniques as well as an examination of the oil extracts to determine the composition of the minor constituents such as phytosterol and antioxidant composition. The oxygen radical absorbance capacity (ORAC) of the tomato seed oils were also measured and correlated with antioxidant contents. This research demonstrated that tomato seed oil yield was highest using hot ethanol and followed by hot hexane and finally $\mathrm{SC}-\mathrm{CO}_{2}$. The $\mathrm{SC}-\mathrm{CO}_{2}$ treatment, however, had the highest total phytosterol content as well as highest individual phytosterol content. Sitosterol, cycloartanol, and stigmasterol were the most abundant phytosterols present in the extracts. The highest concentrations of antioxidants were found in the hexane extract. The most abundant antioxidants found in the tomato seed oils were all-trans-lycopene, cis-3-lycopene and $\beta$-carotene. ORAC was highest for the hexane extract. Oil yield was inversely proportional to both $\alpha$-tocopherol and $\gamma$-tocopherol content and positively correlated with cis-3-lycopene content. ORAC values were positively
\end{abstract}

Names are necessary to report factually on available data; however, the USDA neither guarantees nor warrants the standard of the product, and the use of the name USDA implies no approval of the product to the exclusion of others that may also be suitable.

F. J. Eller $(\bowtie)$ J. K. Moser · J. A. Kenar · S. L. Taylor Functional Foods Research, National Center for Agricultural Utilization Research, Agricultural Research Service,

US Department of Agriculture, 1815 North University Street, Peoria, IL 61604, USA

e-mail: fred.eller@ars.usda.gov correlated with only all-trans-lycopene and cis-3-lycopene demonstrating their role as antioxidants in the tomato seed oil.

Keywords Tomato seed oil - Supercritical carbon dioxide - Accelerated solvent extraction - Phytosterol . Antioxidant · ORAC

\section{Introduction}

In 2002, ca. 12 million tons of tomatoes were canned and the commercial processing of tomatoes produces large amounts of waste [1,2], with between 33 and $40 \%$ of the raw tomatoes ending up as processing waste [3, 4]. Seeds and skins constitute the main waste by-product of the tomato processing industry $[5,6]$. To maximize profits, tomato processors need to find uses for these waste materials. Tomato seeds have been shown to contain ca. 20\% oil [7] with a fatty acid composition of tomato seed essentially like that of low linolenic soybean oil [8]. It has been suggested that tomato seeds would be a good source of salad oil [9].

Tomato seed oil has previously been effectively extracted using supercritical $\mathrm{CO}_{2}\left(\mathrm{SC}-\mathrm{CO}_{2}\right)[6,10]$. In addition, $\mathrm{SC}-\mathrm{CO}_{2}$ has been used to extract minor constituents from tomatoes, including phytosterols [11], tocopherols $[11,12], \beta$-carotene $[6,11-13]$ and lycopene $[6,11-16]$. Although tomato products have been shown to contain high levels of both the carotenoids, $\beta$-carotene and lycopene [17] and carotenoids have excellent antioxidant activity due to their ability to quench singlet oxygen and trap peroxyl radicals $[18,19]$, very little is known about the antioxidant capacity of tomato seed oil.

The objective of this research was to use $\mathrm{SC}-\mathrm{CO}_{2}$ and pressurized solvent extraction ( $n$-hexane and ethanol) for 
the extraction of oil from tomato seeds, determine the sterol, tocopherol and carotenoid contents of the resulting tomato seed oils as well as investigate the antioxidant capacity of the oils.

\section{Experimental}

\section{Materials}

Tocopherol standards ( $\geq 95 \%$ purity), cholesterol and stigmasterol were purchased from Matreya, Inc. (Pleasant Gap, PA, USA). Campesterol, brassicasterol and cycloartenol were from Steraloids (Newport, RI, USA). Cholestane, sitosterol, sitostanol, $\beta$-carotene and lycopene were from Sigma-Aldrich, Inc. (St. Louis, MO, USA). Each phytosterol standard was $\geq 97 \%$ purity. N,O-bis(trimethylsilyl)fluoroacetamide with $1 \%$ trimethylchlorosilane (BSTFA $+1 \%$ TMCS) was purchased from Regis (Morton Grove, IL, USA). Sodium fluorescein, 2,2'-azobis(2-amidinopropane) dihydrochloride (AAPH), Trolox (6-hydroxy-2,5,7,8-tetramethylchroman-2-carboxylic acid), and methyl- $\beta$-cyclodextrin were purchased from Sigma Aldrich (St. Louis, MO, USA) and used as received. Potassium phosphate dibasic and sodium phosphate monobasic were obtained from Fisher Scientific.

\section{Tomato Seed Oil Extractions}

Ground tomato seed samples were obtained from Morning Star (Los Banos, CA, USA) and were shipped frozen. The ground tomato seeds had an average particle size of $0.64 \mathrm{~mm}$ and a moisture content of $8.4 \%$. Three methods of extraction were tested for comparison: supercritical carbon dioxide $\left(\mathrm{SC}-\mathrm{CO}_{2}\right)$, and accelerated solvent extraction using $n$-hexane (Hexane ASE) and accelerated solvent extraction using ethanol (Ethanol ASE). Supercritical carbon dioxide extractions were conducted using a pilot plant extractor previously described [20]. The extraction cell held ca. $1.5 \mathrm{~kg}$ ground tomato seeds and the extraction conditions were as follows: $80{ }^{\circ} \mathrm{C}$ and $55.2 \mathrm{MPa}$ and a flow rate of ca. $0.3 \mathrm{~kg}$ $\mathrm{CO}_{2} / \mathrm{min}$. These conditions are known to be very effective for extracting triglycerides [20]. A reduced pressure receiver $\left(50{ }^{\circ} \mathrm{C}\right.$ and $8.3 \mathrm{MPa}$ ) was used to collect the extract. A solvent:feed ratio of 8.5:1 was used to give a sample large enough for determining the chemical composition, although a higher solvent:feed would have undoubtedly given a higher yield. A Dionex Accelerated Solvent Extractor (ASE) 300 (Dionex Corp., Sunnyvale, CA) was used to extract the ground tomato seeds using $n$-hexane and absolute ethanol. The sample size was ca. $0.6 \mathrm{~g}$ and the extraction conditions were the same for both solvents as follows: $100{ }^{\circ} \mathrm{C}$, 1,500 psi, 7 min static, 3 cycles, $60 \mathrm{~s}$ purge. Extracts were dried under a gentle stream of nitrogen to a constant weight. All yield data (g oil $/ 100 \mathrm{~g}$ seeds) were based on the fresh weight of the tomato seeds. There were three replications of each extraction method.

\section{Compositional Analyses}

For phytosterol analyses, tomato seed oils (ca. $100 \mathrm{mg}$ ) were saponified in $2 \mathrm{~N} \mathrm{KOH}$ in ethanol at $60{ }^{\circ} \mathrm{C}$ for $45 \mathrm{~min}$. Phytosterols were extracted twice with $2 \mathrm{ml}$ hexane. The combined hexane fractions were dried under nitrogen. Trimethylsilyl (TMS) derivatives of the phytosterols were made by adding $100 \mu \mathrm{l}$ each pyridine and $\mathrm{N}, \mathrm{O}$-bis (trimethylsilyl)-fluoroacetamide with $1 \%$ trimethylchlorosilane (Regis Tech., Morton Grove, IL, USA) and heating at $60{ }^{\circ} \mathrm{C}$ for $1 \mathrm{~h}$ on a heating block. For quantitation, $1 \mu \mathrm{l}$ of each sample was manually injected, in triplicate, onto a Varian (Palo Alto, CA) 3400 gas chromatograph (GC) equipped with a flame ionization detector (FID), and a Supelco (Bellefonte, PA, USA) $\mathrm{SPB}^{\mathrm{TM}}-1701$ $(30 \mathrm{~m} \times 0.25 \mathrm{~mm} \times 0.25 \mu \mathrm{m})$ capillary column. Helium was used as a carrier gas, with a flow rate of $1 \mathrm{ml} / \mathrm{min}$ and a 1:50 injector split. Injector temperature was $270{ }^{\circ} \mathrm{C}$, and detector temperature was $290{ }^{\circ} \mathrm{C}$. The column oven initial temperature was $250{ }^{\circ} \mathrm{C}$ for $0.5 \mathrm{~min}$, increased at $10^{\circ} \mathrm{C} / \mathrm{min}$ to $270^{\circ} \mathrm{C}$ and held for $27 \mathrm{~min}$, then increased at $10{ }^{\circ} \mathrm{C} / \mathrm{min}$ to $280{ }^{\circ} \mathrm{C}$ and held for $3.5 \mathrm{~min}$. Data collection and integration were performed using Varian Galaxie Chromatography Software Ver. 1.9.3.2. Cholesterol, cholestane, brassicasterol, campesterol, stigmasterol, sitosterol, and cycloartenol were identified by comparison of their retention times (RT) and confirmed by gas-chromatography mass-spectrometry (GC-MS). Quantitation was carried out by the internal standard (IS) method using $50 \mu \mathrm{g}$ cholestane as IS with a minimum of four levels for each standard. For phytosterols with no available commercial standard, the response factor for $\beta$-sitosterol was used for quantitation. GC-MS was used to assist in identifying sterols with no commercially available standards. GC-MS analyses were performed on an Agilent (Santa Clara, CA, USA) 6890 GC-MS equipped with a HP-5MS capillary column $(30 \mathrm{~m} \times 0.25 \mathrm{~mm} \times 0.25 \mu \mathrm{m})$, a 5973 mass selective detector, and a 7683 autosampler. The transfer line from GC to the MSD was set to $280{ }^{\circ} \mathrm{C}$. The injector and oven temperature programs were the same as described for the GC-FID instrument above. MSD parameters were as follows: scan mode, 50-600 amu, ionizing voltage, $70 \mathrm{eV}$, and EM voltage, $1,823 \mathrm{~V}$. Mass spectral identification was performed using the Wiley MS database combined with comparison to literature values for RT and mass spectra (see details in "Results and Discussion").

For determination of tocopherol content, tomato seed oil extracts (ca. 50-60 mg) were weighed into test tubes and 
$1 \mathrm{ml}$ of hexane added. The tubes were mixed by vortex for 30-60 s, then filtered through a $0.45 \mu \mathrm{m}$ filter (Chrom Tech, Inc., Apple Valley, MN, USA) and these diluted extracts were immediately analyzed in triplicate by HPLC. Analyses were carried out with a Thermo Separation Products (San Jose, CA, USA) SpectraSYSTEM pump and autosampler connected to a SpectraSYSTEM FL fluorescence detector. Samples $(50 \mu \mathrm{l})$ were injected onto a YMC-Pack-Diol-NP, $5 \mu \mathrm{m}, 4.6 \times 250 \mathrm{~mm}$ column (YMC, Wilmington, NC, USA). The mobile phase consisted of 98:2 v/v hexane: 2-propanol with a continuous flow rate of $1.5 \mathrm{ml} / \mathrm{min}$. Tocopherols were identified based upon retention time similarity with known standards using fluorescence detection (excitation: $292 \mathrm{~nm}$, emission: $344 \mathrm{~nm}$ ). Quantitation was carried out using external calibration with pure standards injected at concentrations between 5 and $50 \mu \mathrm{g} / \mathrm{ml}$ for $\alpha$ - and $\gamma$-tocopherols, and between 0.5 and $20 \mu \mathrm{g} / \mathrm{ml}$ for $\delta$-tocopherol.

For $\beta$-carotene and lycopene analyses, tomato seed oil extracts were diluted to $50 \mathrm{mg} / \mathrm{ml}$ in $50: 50(\mathrm{v} / \mathrm{v})$ methanol:methyl tert-butyl ether (MTBE), and were injected onto a Shimadzu (Columbia, MD, USA) HPLC system with an LC20AT HPLC pump, DGU-20A membrane degasser, SIL-10AF autosampler and SPD-M20A diode array detector. Separation of $\beta$-carotene and lycopene was performed using the solvent gradient described by Sass-Kiss et al. [21] using a YMC (Kyoto, Japan) C30 column (3 $\mu \mathrm{m}$, $250 \times 4.6 \mathrm{~mm}$ i.d.) [21]. Peaks were scanned from 200 to $550 \mathrm{~nm}$, the detection wavelength was $450 \mathrm{~nm}$. Carotenoids were identified by retention time compared to known standards as well as by spectral characteristics. Quantitation was carried out by the external standard method using $\beta$-carotene standards solutions ranging from $13.3 \mathrm{ng} / \mathrm{ml}$ to $1.3 \mu \mathrm{g} / \mathrm{ml}$, and lycopene standard solutions ranging between 0.5 and $2.5 \mu \mathrm{g} / \mathrm{ml}$. Concentrations of the initial stock solutions were determined using the extinction coefficients for each standard. The lycopene standard was declared by Sigma to be $\geq 90 \%$ pure, however, HPLC analysis revealed that the standard had three peaks besides the all-trans-lycopene isomer, which accounted for $70 \%$ of the total peak area. The three other peaks were tentatively identified as cis-lycopene isomers based on their spectral and retention characteristics compared to other reports of the cis-lycopene isomer analysis by HPLC [22, 23]. Samples with peaks eluting at the same retention time and with the same spectral characteristics were identified as cis-isomers and their quantitation was determined using the same standard curve for the all-trans isomer.

Lipophilic Oxygen Radical Absorbance Capacity $\left(\mathrm{L}-\mathrm{ORAC} \mathrm{FL}_{\mathrm{F}}\right)$ Analyses

Lipophilic $\mathrm{ORAC}_{\mathrm{FL}}$ assays were performed similarly to those described by Prior and coworkers [24, 25] and the previous report by Haung et al. [26] with minor modification to allow the use of standard cuvettes instead of a microplate reader. Magnetically stirred reaction solutions in plastic cuvettes (Fisher, Cat\# 14-955-130) were monitored at an excitation wavelength of $485 \mathrm{~nm}$ and an emission filter of $520 \mathrm{~nm}$ using a Varian Cary Eclipse Fluorometer (VIC, Australia) equipped with a circulating water jacket to maintain cell temperature at $37^{\circ} \mathrm{C}$. Fluorescence was followed using the Varian Cary Eclipse kinetics software package. AAPH was used as the peroxyl generator and Trolox as the standard. Final L-ORAC $\mathrm{FL}_{\mathrm{FL}}$ values are given in $\mu \mathrm{mol}$ of Trolox equivalents/g ( $\mu \mathrm{mol}$ Tequiv/g) oil by using the standard curve calculated for each assay.

Extracted tomato seed oil extracts sample were accurately weighed (10.0-15.0 mg) and dissolved in $1.0 \mathrm{ml}$ of acetone and then diluted with $9 \mathrm{ml}$ of $50 \%$ acetone $/ 50 \%$ water, v/v containing $7 \%$ randomly methylated $\beta$-cyclodextrin (RMCD) as a solubility enhancer. Samples were shaken at room temperature on an orbital shaker operating at $400 \mathrm{rpm}$ for $1 \mathrm{~h}$ before use. The 7\% RMCD solution was used to perform further dilutions of samples as needed, for the blank, and to dissolve the Trolox standards for the lipophilic assay.

A $100-\mu \mathrm{M}$ stock solution of Trolox was prepared in $75 \mathrm{mM}$ phosphate buffer, $\mathrm{pH} 7$, and divided into $1-\mathrm{ml}$ aliquots that were stored at $-20{ }^{\circ} \mathrm{C}$ until use. A new set of stock Trolox vials were removed from the freezer daily for use and Trolox calibration standards at (20, $4060 \mu \mathrm{M})$ were run for each sample to obtain the necessary standard curves.

Fresh fluorescein solutions $\left(9.6 \times 10^{-8} \mathrm{M}\right)$ utilized for the L-ORAC $_{\mathrm{FL}}$ assays were prepared daily by diluting $320 \mu \mathrm{l}$ of a stock fluorescein solution $\left(5.9 \times 10^{-6} \mathrm{M}\right.$; stored at $-20{ }^{\circ} \mathrm{C}$ in the dark until needed) in $20 \mathrm{ml}$ of 75-mM phosphate buffer, $\mathrm{pH} 7$.

A stock standard solution of AAPH (172 mg) in 75-mM phosphate buffer, pH 7 (20 ml), was prepared daily for use as the rate of peroxyl generation from AAPH is temperature sensitive.

To conduct the $\mathrm{L}-\mathrm{ORAC} \mathrm{FL}_{\mathrm{FL}}$ assay, $100 \mu \mathrm{l}$ of lipophilic sample solution was added to the fluorescein stock solution $\left(2.4 \mathrm{ml}\right.$ of $\left.9.6 \times 10^{-8} \mathrm{M}\right)$ in a cuvette containing a magnetic stir bar. The solution was equilibrated for $30 \mathrm{~min}$ at $37{ }^{\circ} \mathrm{C}$ then initiated by the addition of AAPH $(750 \mu \mathrm{l})$. Fluorescence was recorded immediately every minute until the reading declined to less than $5 \%$ of the initial reading (e.g. $40 \mathrm{~min}$ ). Sample replicates were run on different days. The 7\% RMCD solution was used as for the blank and the Trolox standards used to obtain standard curves. Raw data were exported from the Varian Eclipse software to a Microsoft Excel spreadsheet (Microsoft, Roselle, IL, USA) for further analyses. The fluorescence versus time curves 
were normalized to the curve of the blank corresponding to the same assay by multiplying original data by the factor fluorescence $_{\text {blank }, t=0} /$ fluorescence $_{\text {sample }, t=0}$. From the normalized curves, the area under the fluorescence decay curve (AUC) was calculated as

$\mathrm{AUC}=\left(0.5+f_{1} / f_{0}+f_{2} / f_{0}+\cdots+f_{i} / f_{0}\right) \times \mathrm{CT}$

where $f_{0}=$ initial fluorescence reading at cycle 0 , $f_{i}=$ fluorescence reading at cycle $i$, and $\mathrm{CT}=$ cycle time in minutes. The net AUC corresponding to a sample was calculated by subtracting the AUC corresponding to the blank. $\mathrm{L}=\mathrm{ORAC}_{\mathrm{FL}}$ were determined by regression relating Trolox concentrations and the net area under the kinetic fluorescein decay curve for all the samples. L-ORAC $_{\mathrm{FL}}$ values were expressed as Trolox equivalents by using the standard curve calculated for each assay. Final results were in $\mu \mathrm{mol}$ Tequiv/g oil.

Analyses of variance (ANOVA) were conducted on the percentage data using Statistix 7 software (Analytical Software, Tallahassee, FL, USA), main effects were tested using $F$ tests and means were compared using least significant difference (LSD) $(P=0.05)$. Correlation coefficients were determined between individual antioxidant content and oil yield as well as ORAC.

\section{Results and Discussion}

\section{Tomato Seed Oil Yields}

The effect of the extraction method on tomato seed oil yield is shown in Fig 1. The highest yield was for the Ethanol ASE, with a yield of $23.1 \%$ followed by the Hexane ASE (20.0\%) and the $\mathrm{SC}-\mathrm{CO}_{2}(17.3 \%)$. The ANOVA indicated that there was a significant extraction treatment effect on oil yield $\left(F_{2,6}=378.6, P=0.0000\right)$. All three extraction treatments were statistically different

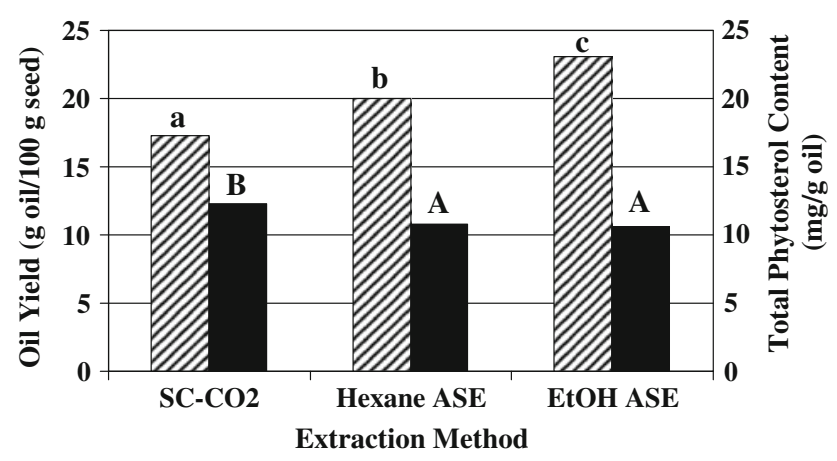

Fig. 1 Effect of extraction method on mean oil yield (diagonal striped bars with lower case letters) and mean total phytosterol content (solid bars with upper case letters). The means without letters in common differ significantly by $\operatorname{LSD}(P=0.05)$ from one another. Although Vági et al. [11] studied tomato pomace instead of tomato seeds and their extraction conditions were similar but not identical, they reported the same trends as were found here with slightly lower values (i.e., $20.3,15.3$, and $15.1 \%$, respectively). The ethanol treatment may have given a slightly higher yield due to the extraction of more polar compounds than the hexane treatment would have extracted. The oil yield for the $\mathrm{SC}-\mathrm{CO}_{2}$ treatment was expected to be more similar to that for the hexane treatment and it is possible that the $\mathrm{SC}-\mathrm{CO}_{2}$ treatment may have given a higher yield if a slightly higher solvent:feed ratio had been used (i.e., greater than the 8.5:1 used here).

\section{Phytosterol Content}

The total phytosterol contents for the extraction treatments are shown in Fig 1. The ANOVA indicated that there was a significant extraction treatment effect on total phytosterol content $\left(F_{2,6}=46.2, P=0.0002\right)$. The total phytosterol content for the $\mathrm{SC}-\mathrm{CO}_{2}$ treatment (i.e., $12.30 \mathrm{mg} / \mathrm{g}$ oil) was significantly higher than both that for the Hexane and Ethanol ASE treatments (i.e., 10.81 and $10.55 \mathrm{mg} / \mathrm{g}$ oil, respectively) which were statistically equivalent. The 4-desmethyl, 4-monomethyl, and 4,4-dimethylsterols from tomato seed oil, along with seeds from several other solanaceous plants, have been extensively characterized by Itoh et al. [27-29], however, the absolute quantity was not determined. These amounts are relatively high compared to other vegetable oils, most of which have a phytosterol content ranging between 2 and $10 \mathrm{mg} / \mathrm{g}$ [30]. Lazos et al. [31] reported an average of $4.55 \mathrm{mg} / \mathrm{g}$ total phytosterols in tomato seed oil, or roughly half of what we found. These differences are likely due to differences in the samples, extraction conditions, and analytical methodology.

Interestingly, the oil yield data and phytosterol content data are clearly inversely proportional. This may be a result of all three extraction treatments extracting essentially all of the phytosterols but the three extraction treatments varying in the amounts of the triglycerides extracted. This resulted in the observed differences in the phytosterol concentrations between the oils. The absolute amounts of phytosterols extracted (calculated by multiplying the oil yield by the phytosterol content) are essentially the same for the SC- $\mathrm{CO}_{2}$, Hexane ASE, and Ethanol ASE treatments (i.e., $2.1,2.2$ and $2.4 \mathrm{mg} / \mathrm{g}$ oil, respectively). This effect is also reflected in the data for the individual phytosterols.

Previous researchers have reported high levels of $\beta$-sitosterol [9, 31, 32], stigmasterol [9, 31, 32], cholesterol $[31,32]$, campesterol [31, 32], and brassicasterol $[9,32]$ in tomato seed oil. All of these phytosterols and several others were found in our tomato seed oils. The mean individual phytosterol contents of the tomato seed oils, $F$ tests and $P$ values from the statistical analyses (i.e., ANOVA) are 
Table 1 Effect of extraction method on individual phytosterol content

\begin{tabular}{|c|c|c|c|c|}
\hline \multirow[t]{2}{*}{ Sterol } & \multicolumn{3}{|c|}{ Mean phytosterol content $(\mathrm{mg} / \mathrm{g})^{\mathrm{a}}$} & \multirow[t]{2}{*}{$F_{2,6}(P$ value $)$} \\
\hline & $\mathrm{SC}-\mathrm{CO}_{2}$ & $\begin{array}{l}\text { Hexane } \\
\text { ASE }\end{array}$ & $\begin{array}{l}\text { Ethanol } \\
\text { ASE }\end{array}$ & \\
\hline Brassicasterol & $0.0367 \mathrm{a}$ & $0.0433 \mathrm{a}$ & $0.0533 \mathrm{a}$ & $0.45(0.6562)$ \\
\hline Campesterol & $0.5900 \mathrm{a}$ & $0.5600 \mathrm{a}$ & $0.5433 \mathrm{a}$ & $4.87(0.0554)$ \\
\hline Dihydrolanosterol & $0.4867 \mathrm{a}$ & $0.4833 \mathrm{a}$ & $0.4467 \mathrm{a}$ & $1.77(0.2483)$ \\
\hline Cycloartenol & $1.340 \mathrm{a}$ & $1.203 \mathrm{a}$ & $1.063 \mathrm{a}$ & $4.51(0.0637)$ \\
\hline Cholesterol & $0.6933 \mathrm{~b}$ & $0.5633 \mathrm{a}$ & $0.5800 \mathrm{a}$ & $58.74(0.0001)$ \\
\hline Cholestanol & $0.1367 \mathrm{~b}$ & $0.0767 \mathrm{a}$ & $0.0767 \mathrm{a}$ & $9.82(0.0128)$ \\
\hline Lathosterol & $0.1300 \mathrm{~b}$ & $0.1133 \mathrm{a}$ & $0.1133 \mathrm{a}$ & $12.50(0.0073)$ \\
\hline Dihydrospinasterol & $0.4667 \mathrm{~b}$ & $0.3900 \mathrm{a}$ & $0.4000 \mathrm{a}$ & $24.68(0.0013)$ \\
\hline Stigmasterol & $1.3567 \mathrm{~b}$ & $1.1300 \mathrm{a}$ & $1.1467 \mathrm{a}$ & $36.21(0.0004)$ \\
\hline Sitosterol & $4.0033 \mathrm{~b}$ & $3.6067 \mathrm{a}$ & $3.5733 \mathrm{a}$ & $28.93(0.0008)$ \\
\hline Cycloartenol & $2.6933 \mathrm{c}$ & $2.3767 \mathrm{~b}$ & $2.2767 \mathrm{a}$ & $60.83(0.0001)$ \\
\hline$\beta$-Amyrin & $0.1733 \mathrm{~b}$ & $0.0967 \mathrm{a}$ & $0.0967 \mathrm{a}$ & $16.03(0.0039)$ \\
\hline Citrostadienol & $0.2033 \mathrm{~b}$ & $0.1833 \mathrm{a}$ & $0.1867 \mathrm{a}$ & $10.33(0.0114)$ \\
\hline
\end{tabular}

${ }^{\text {a }}$ Mean $(n=3)$ in the same row without letters in common differ significantly by $\operatorname{LSD}(P=0.05)$

shown in Table 1. The ANOVAs indicated a significant extraction treatment effect (i.e., $F_{2,6}>5.14$ ) for most individual phytosterols with the exceptions of brassicasterol, campesterol, dihydrolanosterol, and cycloartenol. The three extraction treatments gave similar results, although the $\mathrm{SC}-\mathrm{CO}_{2}$ tended to give the highest contents of any given phytosterol. Phytosterols identified were $\beta$-sitosterol $(\sim 33 \%)$, cycloartanol $(22 \%)$, stigmasterol (10.4-11\%), cycloartenol (10-11\%), cholesterol (5.2$5.6 \%$ ), campesterol (4.8-5.2\%), dihydrolanosterol (and lophenol, 3.9-4.5\%), unknown (3.6-3.8\%), citrostadienol (1.7\%), $\beta$-amyrin (1-1.4\%), lathosterol (1\%), cholestanol $(0.7-1 \%)$, and brassicasterol $(0.3-0.5 \%)$. The identification of $\beta$-sitosterol, stigmasterol, cycloartenol, cholesterol, campesterol, brassicasterol, and cholestanol were confirmed by RT and by GC-MS of known standards, and confirm previous reports of their presence in tomato seed oil $[27,28]$. Lathosterol was identified by GC-MS comparison to the Wiley database. Dihydrolanosterol, $\beta$-amyrin, and citrostadienol were identified based on their mass spectrums and RT compared to the literature [33], confirmed by the fact that these sterols have previously been identified in tomato seed oil [28]. Several ions within the dihydrolanosterol mass spectrum, including $m / e$ 472, 382, 367 , and 269 , indicated that this peak may also have contained a small amount of lophenol, which elutes at the same retention time [33], and is confirmed by the fact that this was previously found to be the most prominent 4-dimethylsterol in tomato seed oil [29]. The cycloartanol peak matched the relative retention time and mass spectra reported by Farines [33], and has also been shown to be the most prominent 4,4 dimethylsterol in tomato seed oil [28], followed by cycloartenol. Cycloartenol elutes at the same $\mathrm{RT}$ as $\Delta 5$-avenasterol, which has been reported by others in tomato seed oil $[27,31,34]$. It is possible that these two peaks were co-eluting, but there were no detectable molecular ions characteristic for $\Delta 5$-avenasterol seen in the mass spectra. An unknown peak representing approximately $3.6-3.8 \%$ of the sterols eluted at an RRT of 0.71 (relative to the retention time of $\beta$-sitosterol). GC-MS analysis revealed that the TMS-ether of this sterol was of the same molecular weight as $\beta$-sitosterol $\left(\mathrm{M}^{+} 486\right)$. There are no known 4-desmethylsterols of this molecular weight that elute at this relative retention time, and there were none of the characteristic molecular ions for either $\Delta 5(\mathrm{~m} / \mathrm{e}$ $129)$ or $\Delta 7$ ( $m / e 229$ or 255$)$ desmethylsterols. Based on the GC-MS data and comparison to values for sterol peaks of the same molecular weight in tomato seed oil, the unknown peak likely consists of one or more of the following 4-monomethylsterols: 31-norcycloartanol, 31-norlanost8-enol, or 31-norlanost-9[11]-enol [29].

The high content of cholesterol, relative to other vegetable oils that usually only contain trace amounts of this sterol [30], is characteristic of phytosterols from the seeds from the Solanaceae $[27,28]$. Also, while many vegetable oils contain primarily 4-desmethylsterols (i.e., sitosterol, stigmasterol, campesterol, cholesterol), and very low to trace amounts of 4-monomethyl, and 4,4 dimethyl sterols [35], tomato seed oil samples had significant quantities of 4-mono-, and 4-dimethylsterols (i.e., citrostadienol, dihydrolanosterol, cycloartenol, cycloartanol, $\beta$-amyrin, and lathosterol).

\section{Tocopherols}

The total tocopherol content ranged from $0.94 \mathrm{mg} / \mathrm{g}$ in the Ethanol ASE tomato seed extracts to 1.08 and $1.11 \mathrm{mg} / \mathrm{g}$ in Hexane ASE and $\mathrm{SC}-\mathrm{CO}_{2}$ extracts of the tomato seeds, respectively (Table 2). These values are in the same range as most crude vegetable oils such as soybean and sunflower oil [30]. Gamma-tocopherol was the dominant homologue, followed by much lower amounts of $\alpha$ - and $\delta$-tocopherol. Lazos et al. [31] reported a similar amount of total tocopherols (i.e., ca. $1.26 \mathrm{mg} / \mathrm{g}$ ), however they reported a much higher amount of $\delta$-tocopherol. The ANOVAs indicated that there were no significant extraction treatment effects for any of the tocopherols.

\section{$\beta$-Carotene and Lycopene}

The concentrations of $\beta$-carotene and lycopene for the three extraction treatment $\mathrm{s}$ are shown in Table 2. The ANOVAs indicated that there were significant extraction treatment effects for $\beta$-carotene and all lycopene isomers. 
Table 2 Effect of extraction method on individual antioxidant content
${ }^{\text {a }}$ Mean $(n=3)$ in the same row without letters in common differ significantly by $\operatorname{LSD}(P=0.05)$

\begin{tabular}{|c|c|c|c|c|}
\hline Antioxidant & $\mathrm{SC}-\mathrm{CO}_{2}$ & Hexane ASE & Ethanol ASE & $F_{2,6}(P$ value $)$ \\
\hline \multicolumn{5}{|c|}{ Mean antioxidant content $(\mathrm{mg} / \mathrm{g})^{\mathrm{a}}$} \\
\hline$\alpha$-Tocopherol & $0.05 \mathrm{a}$ & $0.04 \mathrm{a}$ & $0.03 \mathrm{a}$ & $2.72(0.1445)$ \\
\hline$\gamma$-Tocopherol & $1.05 \mathrm{a}$ & $1.03 \mathrm{a}$ & $0.90 \mathrm{a}$ & $4.93(0.0541)$ \\
\hline$\delta$-Tocopherol & $0.01 \mathrm{a}$ & $0.01 \mathrm{a}$ & $0.01 \mathrm{a}$ & $1.50(0.2963)$ \\
\hline \multicolumn{5}{|c|}{ Mean antioxidant content $(\mu \mathrm{g} / \mathrm{g})^{\mathrm{a}}$} \\
\hline$\beta$-Carotene & $0.93 \mathrm{a}$ & $4.53 \mathrm{~b}$ & $4.06 \mathrm{~b}$ & $10.13(0.0119)$ \\
\hline Lycopene cis 1 & $0.00 \mathrm{a}$ & $1.34 \mathrm{~b}$ & $0.58 \mathrm{a}$ & $11.55(0.0088)$ \\
\hline Lycopene cis 2 & $0.00 \mathrm{a}$ & $3.02 \mathrm{c}$ & $1.06 \mathrm{~b}$ & $42.55(0.0003)$ \\
\hline Lycopene all trans & $0.00 \mathrm{a}$ & $12.07 \mathrm{~b}$ & $7.50 \mathrm{~b}$ & $18.69(0.0026)$ \\
\hline Lycopene cis 3 & $0.00 \mathrm{a}$ & $9.43 \mathrm{~b}$ & $7.85 \mathrm{~b}$ & $13.62(0.0059)$ \\
\hline
\end{tabular}

$\beta$-carotene concentrations were highest for the Hexane ASE and Ethanol ASE treatments with a very low content for the $\mathrm{SC}-\mathrm{CO}_{2}$ extraction. Similarly, lycopene content was highest for the Hexane ASE treatment, followed by the Ethanol ASE with no lycopene detected in $\mathrm{SC}-\mathrm{CO}_{2}$ extracts. Four lycopene peaks were identified in the ASE extracts, and their profile was similar between the two solvents. The all-trans lycopene peak which eluted at 20.11 min was the most predominant in most of the samples, but there was nearly an equal amount of the cis isomer that eluted at $20.51 \mathrm{~min}$, and less abundant content of the two other cis isomers. The predominant form of lycopene in tomato products is the all-trans isomer [22], but analysis of human serum samples reveals that after consumption lycopene is converted predominantly to various $\mathrm{cis}$ isomers. Determination of the various isomers of lycopene in tomato seeds has never been published, so it is not clear if the high content of cis-isomers in these tomato seed oil samples is a result of the natural ratio in the seeds or due to storage and extraction conditions. Ishida et al. [23] showed that in pure trans-lycopene isolated from tomatoes, cis-isomers formed during storage. Isomerization occurred even with storage at $-20{ }^{\circ} \mathrm{C}$, but was accelerated at higher temperatures.

\section{Lipophilic Oxygen Radical Absorbance Capacity $\left(\mathrm{L}-\mathrm{ORAC} \mathrm{FL}_{\mathrm{FL}}\right)$ Analyses}

The mean ORAC values ( $\mu \mathrm{mol} \mathrm{TE} / \mathrm{g}$ ) for the three extraction methods are shown in Table 3. The ANOVA indicated that there was a significant extraction treatment effect on ORAC $\left(F_{2,6}=9.27, P=0.0146\right)$. Although the Hexane ASE gave the highest ORAC value (i.e., 1.47), it was statistically equivalent to that for the Ethanol ASE (i.e., 1.17). The ORAC value for the $\mathrm{SC}-\mathrm{CO}_{2}$ treatment (i.e., 0.96) was significantly lower than those for both the Hexane ASE and the Ethanol ASE treatments. The correlation coefficients for antioxidant content and oil yield as well as antioxidant content and ORAC are shown in Table 4. Only five of the 16 possible correlation coefficients were statistically significant. Both $\alpha$-tocopherol
$(-0.721)$ and $\gamma$-tocopherol $(-0.761)$ were inversely correlated with oil yield, suggesting that the extraction of the triglyceride oil and these tocopherols are quite different. It is likely that the triglyceride oil is more easily extracted than the more polar tocopherols. On the other hand, lycopene $c i s-3$ was positively correlated with oil yield, indicating that these two compounds are extracted in very similar manners or that the presence of the triglyceride oil enhances the solubility of the lycopene. Interestingly, triglyceride oils have been used in conjunction with $\mathrm{SC}-\mathrm{CO}_{2}$ to assist with the extraction of lycopene. Vasapollo et al. [36] describes the use of vegetable oil as a co-solvent with $\mathrm{SC}-\mathrm{CO}_{2}$ for the extraction of lycopene from ground sundried tomatoes. The presence of the vegetable oil as a co-solvent with $\mathrm{SC}-\mathrm{CO}_{2}$ improved both the yield as well as the stability of the lycopene extracts. Similarly, Ciurlia et al. [37] combined the extraction of hazelnut triglycerides with the extraction of lycopene from tomatoes.

The ORAC values were only statistically correlated with lycopene cis (0.748) and lycopene all trans (0.672). This suggests that the antioxidant capacity of tomato seed oil is mainly due to the presence of these two lycopene isomers. Although tomato products have been shown to contain high levels of both the carotenoids, $\beta$-carotene and lycopene [17], lycopene is a stronger antioxidant than $\beta$-carotene and the antioxidant capacity of tomatoes is reported to be related to the lycopene content [38, 39].

In summary, this research demonstrated that tomato seed oil yield was highest using hot ethanol followed by hot hexane and finally $\mathrm{SC}-\mathrm{CO}_{2}$. Although the $\mathrm{SC}-\mathrm{CO}_{2}$ treatment gave a slightly lower oil yield, it gave the highest total phytosterol content as well as for each individual phytosterol content. Sitosterol, cycloartanol, and stigmasterol were the most abundant phytosterols present in the extracts. The highest concentrations of antioxidants were found in the hexane extract with all-trans-lycopene, cis-3lycopene and $\beta$-carotene the most abundant antioxidants present in the extracted oils. Oxygen radical absorbance capacity was highest for the Hexane extract. Oil yield was 
Table 3 Effect of extraction method on oxygen radical absorbance capacity (ORAC)

\begin{tabular}{ll}
\hline Extraction method & Mean ORAC ${ }^{\mathrm{a}}(\mu \mathrm{mol}$ Trolox equiv/g) \\
\hline $\mathrm{SC}-\mathrm{CO}_{2}$ & $0.96 \mathrm{~b}$ \\
Hexane ASE & $1.47 \mathrm{a}$ \\
Ethanol ASE & $1.17 \mathrm{a}$ \\
\hline
\end{tabular}

$\bar{a}$ Mean $(n=3)$ without letters in common differ significantly by $\operatorname{LSD}(P=0.05)$

Table 4 Correlation coefficients for antioxidant content, oil yield and ORAC

\begin{tabular}{lll}
\hline Antioxidant & Oil yield & ORAC \\
\hline$\alpha$-Tocopherol & -0.721 & n.s. \\
$\gamma$-Tocopherol & -0.761 & n.s. \\
$\delta$-Tocopherol & n.s. & n.s. \\
$\beta$-Carotene & n.s. & n.s. \\
Lycopene cis-1 & n.s. & n.s. \\
Lycopene cis-2 & n.s. & 0.748 \\
Lycopene all-trans & n.s. & 0.672 \\
Lycopene cis-3 & 0.668 & n.s. \\
\hline
\end{tabular}

n.s. denotes Pearson's correlation coefficient not significant at $P=0.05$

inversely proportional to both $\alpha$-tocopherol and $\gamma$-tocopherol content and positively correlated with lycopene cis 3 content. ORAC values were positively correlated with only cis-2-lycopene and all-trans-lycopene demonstrating their role as antioxidants in the tomato seed oil. These results indicate that tomato seed oil is a good source of a vegetable oil with beneficial properties due to its high amounts of phytosterols and antioxidants.

Acknowledgments The authors wish to thank Jeffrey Teel, Jeanette Little and Kathy Rennick for their technical assistance.

\section{References}

1. Knoblich M, Anderson B, Latshaw D (2005) Analyses of tomato peel and seed byproducts and their use as a source of carotenoids. J Sci Food Agric 85:1166-1170

2. Kaur D, Wani AA, Oberoi DPS, Sogi DS (2008) Effect of extraction conditions on lycopene extractions from tomato processing waste skin using response surface methodology. Food Chem 108:711-718

3. Ries SK, Stout BA (1962) Bulk handling studies with mechanically harvested tomatoes. Proc Am Soc Hortic Sci 81:479-483

4. Topal U, Sasaki M, Goto M, Hayakawa K (2006) Extraction of lycopene from tomato skin with supercritical carbon dioxide: effect of operating conditions and solubility analysis. J Agric Food Chem 54:5604-5610

5. Al-Wandawi H, Abdul-Rahman M, Al-Shaikhly K (1985) Tomato processing wastes as essential raw materials source. J Agric Food Chem 33:804-807
6. Sabio E, Lozano M, Montero de Espinosa M, Mendes RL, Pereira AP, Palavra AF, Coelho JA (2003) Lycopene and $\beta$-carotene extraction from tomato processing waste using supercritical $\mathrm{CO}_{2}$. Ind Eng Chem Res 42:6641-6646

7. Rabak F (1917) The utilization of waste tomato seeds and skins. US Dept Agric Bull 632:15

8. Firestone D (1999) Physical and chemical characteristics of oils, fats, and waxes. AOCS Press, Champaign

9. Vigo MS, Dasso I, Cattaneo P (1977) Studies on the seeds remaining after the processing of tomatoes. Seed oils, seed meals, and protein "isolate". Fisicas y Nat 29:193-203

10. Roy BC, Goto M, Hirose T (1996) Temperature and pressure effects on supercritical $\mathrm{CO}_{2}$ extraction of tomato seed oil. Inter $\mathrm{J}$ Food Sci Technol 31:137-141

11. Vági E, Simándi B, Vásárhelyiné KP, Daood H, Kéry Á, Doleschall F, Nagy B (2007) Supercritical carbon dioxide extraction of carotenoids, tocopherols and sitosterols from industrial tomato by-products. J Supercrit Fluids 40:218-226

12. Rozzi NL, Singh RA, Vierling RA, Watkins BA (2002) Supercritical fluid extraction of lycopene from tomato processing byproducts. J Agric Food Chem 50:2638-2643

13. Baysal T, Ersus S, Starmans DAJ (2000) Supercritical $\mathrm{CO}_{2}$ extraction of $\beta$-carotene and lycopene from tomato paste waste. J Agric Food Chem 48:5507-5511

14. Gomez-Prieto MS, Caja MM, Herraiz M, Santa-Maria G (2003) Supercritical fluid extraction of all-trans-lycopene from tomato. J Agric Food Chem 51:3-7

15. Nobre BP, Palvra AF, Pessoa FLP, Mendes RL (2009) Supercritical $\mathrm{CO}_{2}$ extraction of trans-lycopene from Portuguese tomato industrial waste. Food Chem 116:680-685

16. Yi C, Shi J, Xue SJ, Jiang Y, Li D (2009) Effect of supercritical fluid extraction parameters on lycopene yield and antioxidant activity. Food Chem 113:1088-1094

17. Krinsky NI (1989) Antioxidant functions of carotenoids. Free Radic Biol Med 7:617-635

18. Burton GW, Ingold KU (1984) $\beta$-Carotene: an unusual type of lipid antioxidant. Science 224:569-573

19. Foote CS, Danny RW (1968) Chemistry of singlet oxygen. VIII. Quenching by $\beta$-carotene. J Am Chem Soc 90:6233-6235

20. Friedrich JP, List GR, Spencer F (1988) Semicontinuous supercritical $\mathrm{CO}_{2}$ system for rapid extraction of jojoba and other oilseeds. In: Baldwin AR (ed) Proceedings 7th Inter. Conf. on Jojoba and its uses. American Oil Chemists' Society, Champaign

21. Sass-Kiss A, Kiss J, Milotay P, Kerek MM, Toth-Markus M (2005) Differences in anthocyanin and carotenoid content of fruits and vegetables. Food Res Int 38:1023-1029

22. Clinton SK, Emenhiser C, Schwartz SJ, Bostwick DG, Williams AW, Moore BJ, Erdman JW (1996) cis-trans Lycopene isomers, carotenoids, and retinol in the human prostate. Cancer Epidemiol Biomarkers Prev 5:823-833

23. Ishida BK, Ma J, Chan B (2001) A simple, rapid method for HPLC analysis of lycopene isomers. Phytochem Anal 12: 194-198

24. Wu X, Beecher GR, Holden JM, Haytowitz DB, Gebhardt SE, Prior RL (2004) Lipophilic and hydrophilic antioxidant capacities of common foods in the United States. J Agric Food Chem 52:4026-4037

25. Prior RL, Hoang H, Gu L, Wu X, Bacchiocca M, Howard L, Hampsch-Woodill M, Haung D, Ou B, Jacob R (2003) Assays for hydrophilic and lipophilic antioxidant capacity (oxygen radical absorbance capacity (ORACFL)) of plasma and other biological and food samples. J Agric Food Chem 51:3273-3279

26. Haung D, Ou B, Hampsch-Woodill M, Flanagan JA, Deemer EK (2002) Development and validation of oxygen radical absorbance capacity assay for lipophilic antioxidants using randomly 
methylated $\beta$-cyclodextrin as the solubility enhancer. J Agric Food Chem 50:1815-1827

27. Itoh T, Tamura T, Matsumoto T (1977) 4-Desmethylsterols in the seeds of solanaceae. Steroids 30(3):425-433

28. Itoh T, Tamura T, Matusumoto T (1977) Triterpene alcohols in the seeds of solanaceae. Phytochemistry 16:1723-1726

29. Itoh $T$, Ishii $T$, Tamura $T$, Matsumoto $T$ (1978) Four new and other $4 \alpha$-methylsterols in the seeds of solanaceae. Phytochemistry 17:971-977

30. Gunstone FD, Harwood JL, Padley FB (1986) Major vegetable oils. In: Gunstone FD, Harwood JL, Padley FB (eds) The lipid handbook, 1st edn. Chapman \& Hall, New York, pp 55-112

31. Lazos ES, Tsaknis J, Lalas S (1998) Characteristics and composition of tomato seed oil. Grasas y Aceites 49:440-445

32. Kiosseoglou B, Boskou D (1989) The composition of free and esterified sterols in tomato seed oil. Oleagineux 44:113-115

33. Farines M, Cocallemen S, Soulier J (1988) Triterpene alcohols, 4-methylsterols, and 4-desmethylsterols of eggplant seed oil: a new phytosterol. Lipids 23:349-354
34. Malecka M (2002) Antioxidant properties of the unsaponifiable matter isolated from tomato seeds, oat grains, and wheat germ oil. Food Chem 79:327-330

35. Kornfeldt A, Croon L-B (1981) 4-dimethyl-, 4-monomethyl-, and 4, 4-dimethylsterols in some vegetable oils. Lipids 16(5):306-314

36. Vasapollo G, Longo L, Rescio L, Ciurlia L (2004) Innovative supercritical $\mathrm{CO}_{2}$ extraction of lycopene from tomato in the presence of vegetable oil as a co-solvent. J Supercrit Fluids 29:87-96

37. Ciurlia L, Bleve M, Rescio L (2009) Supercritical carbon dioxide co-extraction of tomatoes (Lycopersicum esculentum L.) and hazelnuts (Corylus avellana L.): a new procedure in obtaining a source of natural lycopene. J Supercrit Fluids 49:338-344

38. Di Mascio P, Kaiser S, Sies H (1989) Lycopene as the most efficient biological carotenoids singlet oxygen quencher. Arch Biochem Biophys 274:532-538

39. Guil-Guerrero L, Rebolloso-Fuentes MM (2009) Nutrient composition and antioxidant activity of eight tomato (Lycopersicon esculentum) varieties. J Food Comp Anal 22:123-129 